\title{
The Possibilities of Modern Methods of Oxidative Stress and Immune Profile Study in Determining the Predictors of Chronic Inflammatory Process in the Bronchi of Young Beginning Smokers
}

\author{
DOI: $10.17691 /$ stm2015.7.3.11
}

Received March 1, 2015

E.V. Makarova, MD, PhD, Associate Professor, Department of Internal Diseases Propedeutics';

V.A. Vakhlamov, MD, PhD, Tutor, Department of Internal Diseases Propedeutics';

M.L. Shonia, Tutor, Department of Internal Diseases Propedeutics";

N.V. Menkov, MD, PhD, Associate Professor, Department of Internal Diseases Propedeutics ${ }^{1}$;

T.I. Solovyova, PhD, Senior Researcher, Biochemistry Department, Central Scientific Research Laboratory';

E.V. Arkhipova, Junior Researcher, Biochemistry Department, Central Scientific Research Laboratory';

G.N. Varvarina, MD, DSc, Professor, Head of the Department of Internal Diseases Propedeutics';

V.V. Novickov, DSc, Professor, Head of the Department of Molecular Biology and Immunology ${ }^{2}$

${ }^{1}$ Nizhny Novgorod State Medical Academy, 10/1 Minin and Pozharsky Square, Nizhny Novgorod,

603005, Russian Federation;

${ }^{2}$ Lobachevsky State University of Nizhni Novgorod, 23 Prospekt Gagarina, Nizhny Novgorod, 603950, Russian Federation

The aim of the investigation was to assess the possibilities of the modern methods for oxidative stress and immune profile research in determining the predictors of chronic inflammatory process in the young smokers bronchi.

Materials and Methods. 85 students of the I-III-year from Nizhny Novgorod State Medical Academy were examined, among them 30 students (group 1) were non-smokers and 55 students (group 2) were addicted to nicotine. The pulmonary function test, oxidant-antioxidant system, the levels of soluble differentiating molecules of leucocytes and histocompatibility molecules were studied along with general clinical examination methods. Only students with normal pulmonary function test indices were included in the study.

Results. Antioxidant system activation and decreasing intensity of lipid peroxidation was characteristic of young smokers. Thus, statistically significant increase in erythrocytes superoxide dismutase was revealed in group 2, and the indices of maximum luminescence intensity Imax and S light sum were decreased. The smokers showed significant increase in SCD95 apoptosis modulator, growing content of SCD25 and SCD8 immune cells activation markers, growing total fraction of SCD54 adhesion molecules as well as soluble histocompatibility molecules of class I and II.

Conclusion. At the first stages smoking is accompanied by compensatory immune reactions, antioxidant system activation, as well as decreasing lipid peroxidation intensity. Modern methods of researching oxidant-antioxidant system as well as the levels of differentiation and histocompatibility molecules allow studying the subtle mechanisms of smoking impact on the respiratory system at the "pre-obstructive" stage and tracing the appearance of chronic bronchi inflammation predictors.

Key words: tobacco smoking; chronic bronchi inflammation predictors; soluble differentiating leucocyte antigens; lipid peroxidation.

Cigarette smoking is one of the leading mechanisms of exogenous respiratory system impairment resulting in the development of chronic obstructive pulmonary disease (COPD), emphysema, lung cancer $[1,2]$. The pathogenic potential of tobacco smoke includes about 4,700 of different toxic substances contributing to systemic damage of the organism and development of pathological processes in the bronchopulmonary system [3-6]. Smoking activates free-radical processes inducing development of chronic inflammation in the respiratory tract over time $[1,4,7,8]$, including microflora involvement [1, 4].
One of the main tools for body balance control is functioning of oxidant-antioxidant system. Bronchoconstriction and vasoconstriction develop through oxidative mechanisms. Oxidants take part in DNA degradation, surfactant activity decrease, hyperpermeability of endothelium and epithelium, cause emphysema and pneumosclerosis [7, 9].

One of the end products of lipid peroxidation (LPO) is malondialdehyde (MDA) whose formation rate enables to estimate the activation of reactions leading to free radicals generation. On the other hand, proteins and antioxidant system enzymes, such as superoxide

For contacts: Makarova Ekaterina Vadimovna, e-mail: e_makarowa@mail.ru 
dismutase (SOD), glutathione peroxidase and others, protect the organism cells from the damaging impact of oxidative stress.

Pro-oxidant-antioxidant system imbalance underlies the development of respiratory system diseases (COPD, bronchial asthma, lung fibrosis, lung cancer), atherosclerosis, ischemic heart disease and others [10-12].

Oxidative stress in the lungs induces modification of plasma proteins, macrophagocytes activation and neutrophils recruitment in the central and peripheral airways, accumulation of toxic LPO products in the lung and blood membranes, increase in LPO products content, hydrogen peroxide, nitrosothiols and nitrates in the expired air [13]. Besides, according to the latest data, it provokes hyperplasia of gland mucous membranes and apoptosis of airway epithelium cells [8].

The mechanisms of inflammation development are in many ways connected with the processes taking place in the immune system. The cells participating in the immune response and inflammation development in COPD have diverse membrane antigens characterizing their lineage [14, 15]. Membrane proteins of immune system cells may have soluble forms which can be found in body fluids (blood serum, synovial fluid and others) and tend to preserve their biological potential regulating different stages of immune response [14, 15]. According to the experts in the field, the content of these molecular markers may be regarded as additional criteria of inflammation activation and COPD severity [3].

Three main groups of soluble membrane proteins have been identified within immune system cells $[14,15]$ :

molecules of the major histocompatibility complex (HLA) class I and II;

cytokine receptors, such as CD25 antigen, interleukin-2 receptor (IL-2 R $\alpha)$;

different antigens participating in immune system cells maturation and performing effector functions: CD95 (Fas/Apo-1) mediates apoptosis, CD50 and CD54 are intercellular adhesion molecules (ICAM), CD38 participates in adhesion, signal transduction and cell activation processes, CD8 is a co-receptor of T-cell receptor and a cytolytic lymphocyte antigen.

One of the 12 most urgent scientific COPD problems specified by the European Respiratory Society is studying the mechanisms of COPD formation at the initial stages and developing methods of early diagnosis of this disease [16]. Garey et al. [5] found neutrophils increased hemotoxic activity combined with other inflammation signs induced by tobacco smoke in the exhaled condensate of the young "apparently healthy" smokers. In the literature there are no clear data on how fast the first COPD signs associated with smoking may occur. The presence of inflammation in the bronchi, immune mechanisms activation as well as destabilization of oxidant and antioxidant balance are likely to be assumed even at the early stages of tobacco addiction. In this connection, it is interesting to trace the onset of chronic inflammatory process development in young beginning smokers by analysing LPO dynamics, antioxidant system activity and soluble membrane proteins of the immune system cells.

The aim of the investigation was to assess the potential of modern methods used for oxidative stress and immune profile study in diagnosing the predictors of chronic inflammatory process in the bronchi of young beginning smokers.

Materials and Methods. The study was performed at the Department of Internal Diseases Propedeutics of Nizhny Novgorod State Medical Academy. There were examined 85 I-III-year students from the Department of General Medicine and the Department of Pediatrics (on average $19.5 \pm 0.7$ years of age; 48 young males and 37 females). Group 1 consisted of 30 non-smoking students and group 2 included 55 students addicted to smoking (30 young males and 25 females). To exclude bronchoobstructive syndrome and other respiratory pathology chest X-ray and pulmonary function test (PFT) data were analyzed: forced expiratory volume per $1 \mathrm{~s}$ (FEV1), Tiffeneau index, peak expiratory flow rate (PEFR), maximal expiratory flow at $25,50,75 \%$ of expiration (MEF25, MEF50, MEF75). The students with pathologic abnormalities were not included in the study.

The intensity of free-radical processes was evaluated by using the induced chemiluminescence method with the aid of biochemiluminometer BCL-07 (Russia). The index of maximum luminescence intensity (Imax) indicating the potential capacity of biological tissues for free-radical oxidation was used for LPO evaluation. Increase in $S$ light sum being an integral indicator of non-enzymatic antioxidant activity (AOA) of plasma and being in an inverse relationship with it may indicate high LPO activity and reduced antioxidant capacity. Plasma MDA level, SOD and erythrocyte catalase activity were also measured.

Imax and MDA levels were considered the criteria of LPO intensity. The antioxidant capacity was evaluated taking into account SOD, catalase and S light sum activity.

The immune system status was assessed by the level of sCD95 apoptosis inhibitor (total and oligomeric fractions), immune cell activation markers (SCD38, sCD25, sCD8), sCD54 intercellular adhesion molecules (ICAM-1), total and oligomeric fraction and SCD50 (ICAM-3), as well as HLA-I and HLA-DR soluble histocompatibility molecules.

The level of soluble membrane antigens was measured with the aid of Stat Fax 2100 enzyme immunoassay device (USA) with the wave length of 450 and $630 \mathrm{~nm}$. The resulting data were expressed in standard units $(\mathrm{U} / \mathrm{ml})$.

The study of soluble differentiating leucocyte antigens was carried out at the Scientific Research Institute of Molecular Biology and Regional Ecology of Lobachevsky 
State University of Nizhni Novgorod. The LPO and AOA study was conducted in Central Scientific Research Laboratory, Nizhny Novgorod State Medical Academy.

The material was statistically processed with Statistica 7.0 and Minitab 16 software. The results were presented as the mean and standard deviation $(\mathrm{M} \pm \mathrm{SD})$. T-test and Mann-Whitney U-test were used depending on the correctness of the chosen distribution of the sign for comparison of unrelated groups. Reliability criterion was considered to be a significance level of $p<0.05$. Statistical tendency was estimated to be present at $0.05<p \leqslant 0.1$.

Results and Discussion. All the students under study had similarly good PFT indices regardless of tobacco addiction (Table 1). Moreover, they did not show clinical signs of inflammatory lesion in the bronchi.

When comparing the indices of LPO and antioxidant enzymes of plasma and hemolysate of erythrocytes our study revealed significant differences between smoking and non-smoking students. Antioxidant system activation was characteristic of young smokers (Table 2, Figure). So, SOD level of erythrocytes in group 2 was statistically significantly higher than in group $1(p=0.0001)$. It should be emphasized that high level of antioxidants (SOD and glutathione) in healthy smokers, which depends on smoking intensity, was found by other authors as well [17].

Table 1

The main spirometric parameters (\%) in young smokers and non-smoking relatively healthy students $(M \pm S D)$

\begin{tabular}{lccc}
\multicolumn{1}{c}{ Index } & Non-smokers & Smokers & $\mathbf{p}$ \\
\hline FEV1 & $89.94 \pm 13.99$ & $91.85 \pm 11.89$ & 0.635 \\
\hline Tiffeneau index & $119.0[119.0 ; 119.75]$ & $121.0[118 ; 121]$ & 0.248 \\
\hline PEFR & $92.19 \pm 14.86$ & $84.29 \pm 13.08$ & 0.076 \\
\hline MEF25 & $147.13 \pm 32.98$ & $149.27 \pm 30.09$ & 0.830 \\
\hline MEF50 & $119.31 \pm 23.41$ & $115.50 \pm 17.91$ & 0.555 \\
\hline MEF75 & $101.44 \pm 14.87$ & $94.48 \pm 14.19$ & 0.135 \\
\hline
\end{tabular}

Note. FEV1: forced expiratory volume per $1 \mathrm{~s}$; PEFR: peak expiratory flow rate; MEF25, MEF50, MEF75: maximal expiratory flow at $25,50,75 \%$.

Table 2

Comparative analysis of lipid peroxidation and antioxidant enzyme indices in smoking and non-smoking students $(M \pm S D)$

\begin{tabular}{|c|c|c|c|}
\hline Index & Non-smokers & Smokers & $\mathbf{p}$ \\
\hline $\begin{array}{l}\text { SOD (enzymatic activity } \\
\text { units/g Hb.min) }\end{array}$ & $280.32 \pm 130.98$ & $585.60 \pm 259.05$ & 0.0001 \\
\hline $\begin{array}{l}\text { Catalase (enzymatic } \\
\text { activity units/g Hb.min) }\end{array}$ & $11.09 \pm 0.19$ & $13.78 \pm 5.53$ & 0.067 \\
\hline MDA (nmol/L) & $1.01 \pm 0.19$ & $1.09 \pm 0.30$ & 0.421 \\
\hline $\operatorname{Imax}(\mathrm{mV})$ & $27.97 \pm 5.77$ & $23.58 \pm 2.19$ & 0.005 \\
\hline$S(m V)$ & $2.53 \pm 0.94$ & $1.74 \pm 0.81$ & 0.032 \\
\hline
\end{tabular}

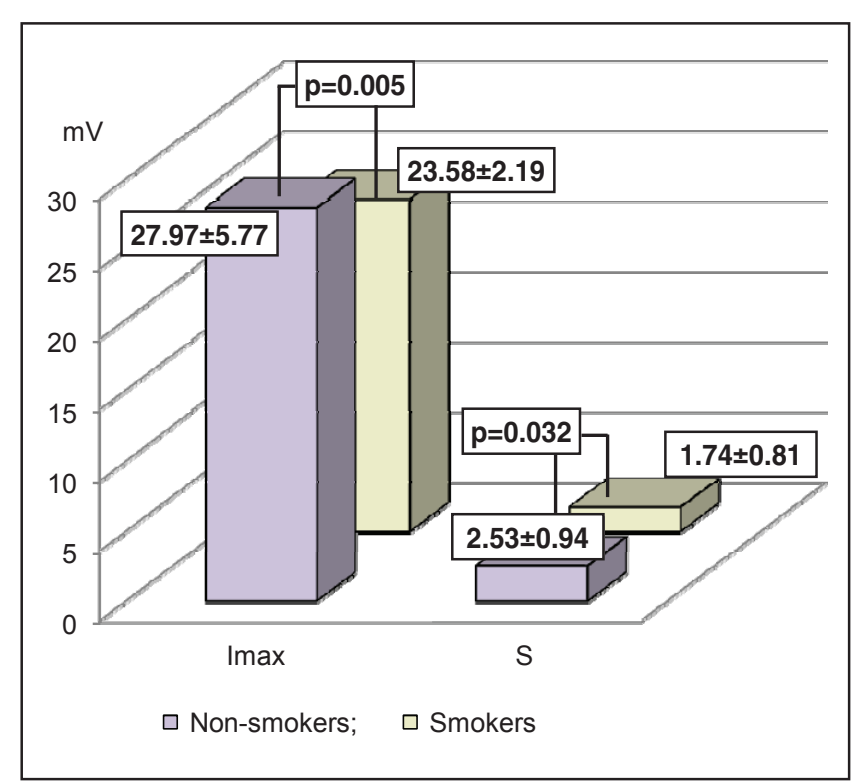

Lipid peroxidation parameters in smoking and non-smoking students

Increase in average values of erythrocyte catalase in group 2 as compared to group 1 was in accordance with the statistical tendency $(p=0.067)$. According to the data provided by the recognized investigators, this index does not alter even in a severe COPD case [18].

On the other hand, in group 2 there was a statistically significant decrease in the index of maximum luminescence intensity Imax indicating the potential capacity of biological tissues for free-radical oxidation $(p=0.005)$ and decrease in $S$ light sum value $(p=0.032)$.

Nowadays there is active research concerning the immune status in many diseases, including COPD. What we do find rather interesting to study is the level of soluble differentiating molecules and histocompatibility molecules in the serum of smoking and non-smoking students.

In our study (Table 3) smoking students were characterised by statistically significant increase in sCD95 apoptosis inhibitor level of both total (sCD95) and oligomeric ( $s C D 950)$ fractions $(p=0.011$ and $p=0.010$, respectively). These results are consistent with the obtained earlier experimental data showing that tobacco smoke extract causes intracellular accumulation of the active oxygen forms and induces Fas/Apo-1-associated apoptosis of alveolar epithelium [19].

Besides, in young smokers immune cells activity grew statistically significantly, which was proved by the changes in SCD8 and SCD25 levels (in the smoking group they appeared to be statistically significantly high: $p=0.029$ and $p=0.0001$, respectively) as well as the level of sCD54 adhesion molecules total fraction ( $p=0.025)$. By contrast, oligomeric fraction values were somewhat increased in non-smokers $(p=0.05)$.

Other authors also found increase in both cellular expression and serous level of soluble adhesion molecules 
Table 3

The level of soluble differentiating molecules and histocompatibility molecules in the serum of smoking and non-smoking students (Me [25; 75])

\begin{tabular}{|cccc}
\hline Index (U/mI) & Non-smokers & Smokers & $\mathbf{p}$ \\
\hline sCD95s & $372.58[244.45 ; 449.20]$ & $533.60[238.47 ; 954.57]$ & $\mathbf{0 . 0 1 1}$ \\
\hline sCD95ol & $241.20[219.17 ; 287.80]$ & $276.45[251.33 ; 358.90]$ & $\mathbf{0 . 0 1 0}$ \\
\hline sCD8 & $382.80[369.55 ; 389.77]$ & $496.10[366.73 ; 1052.33]$ & $\mathbf{0 . 0 2 9}$ \\
\hline sCD38s & $196.20[184.13 ; 206.13]$ & $177.15[107.18 ; 318.07]$ & 0.523 \\
\hline sCD380l & $254.90[234.38 ; 261.25]$ & $249.50[150.35 ; 334.05]$ & 0.880 \\
\hline sCD25 & $405.20[397.25 ; 414.58]$ & $526.5[435.9 ; 645.8]$ & $\mathbf{0 . 0 0 0 1}$ \\
\hline sCD54s & $65.70[56.0 ; 70.25]$ & $75.65[63.95 ; 95.22]$ & $\mathbf{0 . 0 2 5}$ \\
\hline sCD540I & $148.65[130.18 ; 170.82]$ & $127.40[97.18 ; 177.20]$ & 0.05 \\
\hline sCD50 & $361.50[333.68 ; 416.28]$ & $373.60[317.50 ; 571.05]$ & 1.0 \\
\hline HLA-I & $1041.8[966.9 ; 1109.3]$ & $1601.8[1134.7 ; 1987.6]$ & $\mathbf{0 . 0 0 3}$ \\
\hline HLA-DR & $104.30[91.70 ; 115.93]$ & $266.60[116.05 ; 337.70]$ & $\mathbf{0 . 0 0 2}$ \\
\hline
\end{tabular}

So, the analysis of smokers lung tissue samples has shown that $T$ cell inflammation with prevailing $\mathrm{CD}^{+}$ cytolytic lymphocytes is the principal response to antigenic stimuli which is induced by tobacco smoke, and the pathogenesis of emphysema is associated with activation of CD95dependent apoptosis [26].

The average values of HLA-I and HLA-DR histocompatibility molecules statistically significantly grew in smoking students $(p=0.003$ and $\mathrm{p}=0.002$, respectively). The latter may testify of the activation of humoral and macrophage components of immune system response realized by $\mathrm{CD}^{+}{ }^{+}$T-lymphocytes in young beginning smokers. According to the data obtained by other researchers,

under the influence of active and passive smoking [20]. Recently it has been shown that tobacco smoke extract and the mediators of lavage fluid extracted from the smokers' distal bronchi elevate ICAM-1 expression and adhesion properties of neutrophils, moreover, they induce pro-inflammatory BLT2-receptors triggering tissue damage mechanisms [21]. The published findings of 10-year-long multi-ethnic investigation (MESA Lung Study) involving 1,865 participants also emphasize that in the general population high sICAM-1 level serves as an independent marker of progressing lung emphysema [22].

Earlier, our working group [23] has established, that longtime tobacco smoking and COPD progressing is associated with the low level of soluble adhesion antigens which correlates with a more extensive microbial colonization of the lower respiratory tract. The revealed decrease in the serous content of molecules under study may indicate the adverse effect of antibiotics and systemic glucocorticosteroids on the immune status during hospital treatment of obstructive pulmonary disease aggravation.

In recent years, the interrelation between adhesion molecules, inflammation and oxidative stress have been actively discussed. It has been demonstrated on the cell culture of retinal pigment epithelium that inflammatory TNF- $\alpha$ effects are mediated by induction of the active oxygen forms and increasing ICAM-1 expression [24]. As the experiment on mice showed, antioxidants $(\alpha-$ tocopherol), in their turn, elevate the resistance to bacterial pneumonia modulating neutrophil recruitment to the lungs by impairment of ICAM-1 antigen expression, its ligand and other adhesion molecules [25]. The data obtained by us support the idea of existing interrelation between smoking-induced oxidative stress, adhesion molecules and soluble leucocyte antigens participating in apoptosis regulation and immune cell activation. This has been proved by the works of other authors as well. histocompatibility molecules class I play a key role in COPD pathogenesis and their level can be regarded as an indicator of this disease severity [27].

Previous investigations [28] show that smoking students of the I-VI courses may already have mild obstructive pulmonary lesions. This research work convincingly demonstrates that these changes are preceded by significant adaptive processes involving many components such as antioxidant process activation and immune shifts. Thus, modern research data on oxidant-antioxidant system as well as the levels of differentiation and histocompatibility molecules may play a key role in understanding the subtle mechanisms of smoking impact on the respiratory system at the "preobstructive" stage and in identifying chronic bronchi inflammation predictors.

Conclusion. In young smokers smoking is accompanied by compensatory immune reactions inducing antioxidant system activation and decreasing LPO intensity. Their erythrocyte SOD level rises and the indices of maximum luminescence intensity Imax and $S$ light sum reduce significantly.

The first years of tobacco smoking are associated with the activation of protection mechanisms in the organism: increase in SCD95 apoptosis inhibitor level, augmentation of immune cell activity and the level of the total fraction of SCD54 adhesion molecules. Moreover, the values of HLA-I and HLA-DR histocompatibility molecules are observed to grow which may speak of the activation of humoral and macrophage components of the immune response.

The modern research methods of oxidant-antioxidant system as well as the levels of differentiation and histocompatibility molecules allow to study the subtle mechanisms of smoking impact on the respiratory system at the "pre-obstructive" stage and to identify the predictors of chronic bronchi inflammation development. 
Study Funding. The study was carried out within the framework of a project part of the state task in the research field (Project No.20.223.2014/K).

Conflicts of Interest. The authors have no conflict of interests to disclose.

\section{References}

1. Bova A.A., Lapitskiy D.V. Modern approaches to the diagnosis and treatment of ischemic heart disease in patients with chronic obstructive pulmonary disease. Meditsinskie novosti 2007; 9: 7-14.

2. Global'naya strategiya diagnostiki, lecheniya i profilaktiki khronicheskoy obstruktivnoy bolezni legkikh (peresmotr $2011 \mathrm{~g}$.) [Global strategy of diagnosis, treatment and prevention of chronic obstructive pulmonary disease (revised in 2011)]. Pod red. Belevskogo A.S. [Belevskiy A.S. (editor)]. Moscow: Rossiyskoe respiratornoe obshchestvo; 2012.

3. Postnikova L.B.,Kubysheva N.I., Boldina M.V., Li T.V., Klimanov I.A., Novikov V.V. Nitrous stress and soluble differentiation molecules in exacerbation of chronic obstructive pulmonary disease. Pul'monologiya 2012; 1: 35-39.

4. Soodaeva S.K. The role of free-radical oxidation in COPD pathogenesis. Atmosfera. Pul'monologiya i allergologiya 2002; 1(4): 24-25.

5. Garey K.W., Neuhauser M.M., Robbins R.A., Danziger L.H., Rubinstein I. Markers of inflammation in exhaled breath condensate of young healthy smokers. Chest 2004; 125(1): 22-26, http://dx.doi.org/10.1378/chest.125.1.22.

6. Chuchalin A.G. Tobacco smoking and respiratory diseases. Russkij medicinskij zurnal 16(22): 1477-1481.

7. Muravlyova L.E., Molotov-Luchanskiy V.B., Kluyev D.A., Demidchik L.A., Kolesnikova E.A. The role of oxidative stress in pathogenesis of chronic obstructive pulmonary disease. Advances in current natural sciences 2012; 9: 12-16.

8. Lin J.L., Thomas P.S. Current perspectives of oxidative stress and its measurement in chronic obstructive pulmonary disease. COPD 2010; 7(4): 291-306, http://dx.doi.org/10.3109/ 15412555.2010 .496818$.

9. Mishina N.A. The peculiarities of the oxidation stress formation in erythrocytes in the patients with chronic obstruction pulmonary disease. Aspirantskiy vestnik Povolzh'ya 2009; 7-8: 42-46.

10. Dworski R. Oxidant stress in asthma. Thorax 2000; 55(Suppl 2): S51-S53, http://dx.doi.org/10.1136/thorax.55. suppl_2.S51.

11. Park H.S., Kim S.R., Lee Y.C. Impact of oxidative stress on lung diseases. Respirology 2009; 14(1): 27-38, http://dx.doi. org/10.1111/j.1440-1843.2008.01447.x.

12. Chuchalin A.G. Chronic obstructive pulmonary disease and comorbidities. Zdorov'ya Ukraini 2010; 3(232): 40-41.

13. Boots A.W., Haenen G.R.M.M., Bast A. Oxidant metabolism in chronic obstructive pulmonary disease. Eur Respir J 2003; 22(Suppl 46): 14s-27s, http://dx.doi.org/10.1183/ 09031936.03.00000403a.

14. Novikov V.V., Evsegneeva I.V. New human differentiation antigens adopted at the VII international workshop. Rossiyskiy bioterapevticheskiy zhurnal 2003; 2(3): 1-4.

15. Novikov V.V., Karaulov A.V., Baryshnikov A.YU. Rastvorimye formy membrannykh belkov kletok immunnoy sistemy [Soluble membrane proteins of immune system cells]. Moscow: MIA; 2008; 249 p.
16. Siafakas N.M., Tzortzaki E.G. Few smokers develop COPD. Why? Respir Med 2002; 96(8): 615-624, http://dx.doi. org/10.1053/rmed.2002.1318.

17. Burlakova E.B., Zhizhina G.P., Gurevich S.M., Fatkullina L.D., Kozachenko A.I., Nagler L.G., Zavarykina T.M., Kashcheev V.V. Biomarkers of oxidative stress and smoking in cancer patients. J Can Res Ther 2010; 6(1): 47-53, http://dx.doi. org/10.4103/0973-1482.63569.

18. Torres-Ramos Y.D., Garcha-Guillen M.L., OlivaresCorichi I.M., Hicks J.J. Correlation of plasma protein carbonyls and C-reactive protein with GOLD stage progression in COPD patients. Open Respir Med J 2009; 3: 61-66, http://dx.doi. org/10. 2174/1874306400903010061.

19. Jiao Z.X., Ao Q.L., Xiong M. Cigarette smoke extract inhibits the proliferation of alveolar epithelial cells and induces apoptosis. Sheng Li Xue Bao 2006; 58(3): 244-254.

20. Scott D.A., Palmer R.M. The influence of tobacco smoking on adhesion molecules profiles. Tab Ind Dis 2002; 1(1): 7-25, http://dx.doi.org/10.1186/1617-9625-1-1-7.

21. Pace E., Ferraro M., Di Vincenzo S., Bruno A., Giarratano A., Scafidi V., Lipari L., Di Benedetto D.V., Sciarrino S., Gjomarkaj M. Cigarette smoke increases BLT2 receptor functions in bronchial epithelial cells: in vitro and ex vivo evidence. Immunology 2013; 139(2): 245-255, http://dx.doi. org/10.1111/imm.12077.

22. Aaron C.P., Schwartz J.E., Bielinski S.J., Hoffman E.A., Austin J.H., Oelsner E.C., Donohue K.M., Kalhan R., Berardi C., Kaufman J.D., Jacobs D.R. Jr., Tracy R.P., Barr R.G. Intercellular adhesion molecule 1 and progression of percent emphysema: the MESA Lung Study. Respir Med 2014; 109(2): 255-264, http://dx.doi.org/10.1016/j.rmed.2014.10.004.

23. Lyubavina N.A., Varvarina G.N., Makarova E.V., Menkov N.V., Belyaeva E.V., Ermolina G.B., Presnyakova N.B., Korolyova V.V., Filatova E.N., Kurnickov G.Yu., Novickov V.V. Serous content of adhesion soluble antigen as a marker of the chronic obstructive pulmonary disease progressing. Sovremennye tehnologii v medicine 2011; 1: 67-71.

24. Thichanpiang P., Wongprasert K. Green tea polyphenol epigallocatechin-3-gallate attenuates TNF- $\alpha$-induced intercellular adhesion molecule-1 expression and monocyte adhesion to retinal pigment epithelial cells. Am J Chin Med 2015; 2: 1-17, http://dx.doi.org/10.1142/S0192415X1550007X.

25. Bou Ghanem E.N., Clark S., Du X., Wu D., Camilli A., Leong J.M., Meydani S.N. The $\alpha$-tocopherol form of vitamin E reverses age-associated susceptibility to streptococcus pneumoniae lung infection by modulating pulmonary neutrophil recruitment. J Immunol 2015; 194(3): 1090-1099, http://dx.doi. org/10.4049/jimmunol.1402401.

26. Majo J., Ghezzo H., Cosio M.G. Lymphocyte population and apoptosis in the lungs of smokers and their relation to emphysema. Eur Respir J 2001; 17 (5): 946-953, http:Ildx. doi. org/10.1183/09031936.01.17509460.

27. Kubysheva N.I., Postnikova L.B., Presnyakova N.B., Novikov V.V. Participation of soluble major histocompatibility class i molecules in the development of chronic obstructive pulmonary desease. Vestnik Nizhegorodskogo universiteta im. N.I. Lobachevskogo 2010; 2(2): 541-543.

28. Gorbunov N.V. Sostoyanie mikrososudistoy reaktivnosti I funktsii vneshnego dykhaniya u kuryashchikh studentovmedikov. Avtoref. dis. ... kand. med. nauk [Microvascular reactivity and external respiratory function in smoking medical students. Abstract for Dissertation for the degree of Candidate of Medical Science]. Astrakhan'; 2013. 